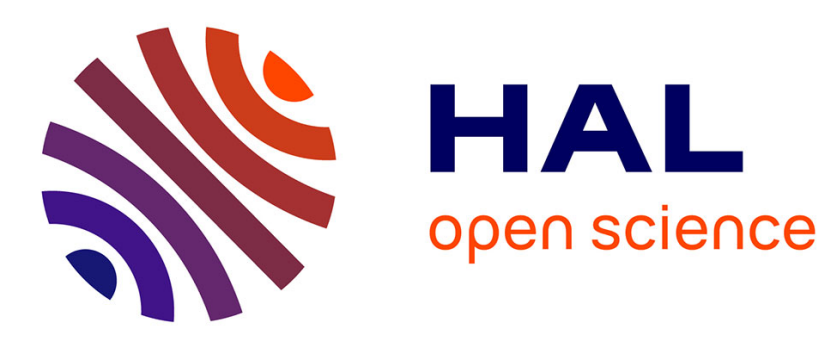

\title{
The categorical role of structurally iconic signs
}

Brent Strickland, Valentina Aristodemo, Jeremy Kuhn, Carlo Geraci

\section{To cite this version:}

Brent Strickland, Valentina Aristodemo, Jeremy Kuhn, Carlo Geraci. The categorical role of structurally iconic signs. Behavioral and Brain Sciences, 2017, 40, pp.E72. 10.1017/S0140525X15003076 . ijn_03053138

\section{HAL Id: ijn_03053138 \\ https://hal.science/ijn_03053138}

Submitted on 10 Dec 2020

HAL is a multi-disciplinary open access archive for the deposit and dissemination of scientific research documents, whether they are published or not. The documents may come from teaching and research institutions in France or abroad, or from public or private research centers.
L'archive ouverte pluridisciplinaire HAL, est destinée au dépôt et à la diffusion de documents scientifiques de niveau recherche, publiés ou non, émanant des établissements d'enseignement et de recherche français ou étrangers, des laboratoires publics ou privés. 
Running head: The categorical role of iconic signs

\section{The categorical role of structurally iconic signs}

Brent Strickland, Valentina Aristodemo, Jeremy Kuhn, Carlo Geraci

Institut Jean Nicod (ENS, EHESS, CNRS),

Departement d'Etudes Cognitives, Ecole Normale Superieure - PSL Research

University, 29 rue d'Ulm, 75005 Paris, France

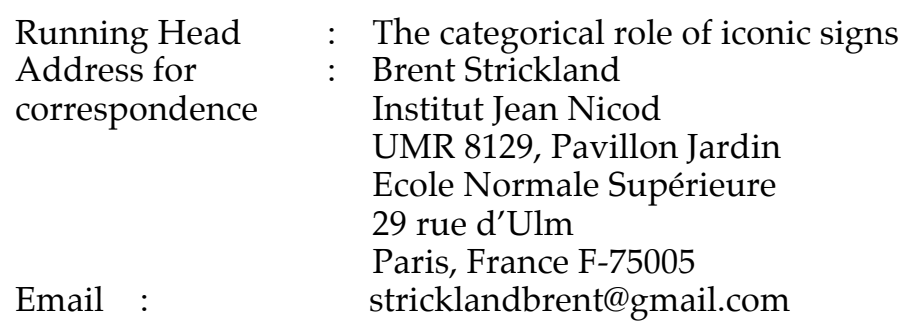

Word count (abstract): 47

Word count (main text): 996

Word count (acknowledgements): 32

Word count (references): 128

Word count (abstract + main text + acknowledgments + references): 1203 
Running head: The categorical role of iconic signs

\begin{abstract}
Goldin-Meadow and Brentari argue that for sign language users gesture, in contrast to linguistic sign, is iconic, highly variable, and similar to spoken language cospeech gesture. We discuss two examples (telicity and absolute gradable adjectives) that challenge the use of these criteria for distinguishing sign from gesture.
\end{abstract}


Running head: The categorical role of iconic signs

In their target article, Goldin-Meadow and Brentari present a subtle view of the distinction between gesture and "categorical" properties of sign language. In both spoken and sign language, illustrative gesture and linguistic material interact within a single unified system that combines meanings in real time. For example, if one were to say the English sentence "a drunk man is walking around" while gesturing with one's hand in a swervy motion, a listener would need to integrate the meaning of the sentence with that of the gesture to correctly interpret the utterance. On the other hand, language and gesture generate meaning in distinct ways. Language is said to use categorical elements that can combine into higher-order structures (e.g. using grammatical rules), while gesture is said to express meaning holistically.

Goldin-Meadow and Brentari argue that the same two expressive categories exist in sign language as in spoken language. However, since many gestures are implemented in the manual modality, it can be difficult to distinguish gesture from the "categorical" elements of sign language. Accordingly, Goldin-Meadow and Brentari provide three heuristics for distinguishing between these. First, gesture tends to be highly variable within a linguistic community while linguistic signs tend to be uniform. Second, gesture tends to be iconic and imagistic whereas sign does not. Finally, gesture in signers tends to be accessible to non-signers, and is often expressed via co-speech gesture in spoken language.

While these criteria can be useful for some examples, here we want to focus on a set of "problem" cases that do not neatly fit within the heuristics laid out by GoldinMeadow and Brentari. In each example, a representation used by signers is highly 
Running head: The categorical role of iconic signs

uniform within signing communities while nevertheless being iconic/imagistic in systematic ways. We argue that careful consideration of these cases requires altering the Goldin-Meadow and Brentari theoretical model and also suggests that cleaner criteria should be adopted for distinguishing between gesture and sign.

First, we consider the case of telicity. Wilbur $(2003,2008)$ argues that the phonetic form of verbs in several sign languages systematically reflects the telicity of the predicate: telic verbs (like decide, whose meaning has an intrinsic culmination point) are marked with rapid deceleration to an abrupt stop; atelic verbs (like ponder, with no intrinsic culmination) are not. Strickland et al. (2015) confirm this generalization across several sign languages (including Italian Sign Language, LIS), and show that even hearing people with no exposure to sign language are able to infer the telicity of a predicate based on the phonetic form of a verb. Following Goldin-Meadow and Brentari's criteria, the accessibility of this correspondence to non-signers likely qualifies it as a gestural component of sign languages.

On the other hand, the phonetic marking of telicity interacts with fully grammaticalized signs in LIS, in a manner invariant from speaker to speaker within a linguistic community. Specifically, in LIS, the phonetic marking of telicity is in complementary distribution with the perfective aspectual marker DONE. Signs like LEAVE, DECIDE or SELL may express perfectivity either by the presence of a clear boundary or by using the lexical sign DONE. In the latter case, telic predicates do not end in an abrupt stop.

Next, we consider absolute gradable adjectives like "full." What defines absolute adjectives is that the adjectival scale includes a maximum degree: when something is 
Running head: The categorical role of iconic signs

completely full, it cannot be any more full. This contrasts with relative adjectives like "rich" which have no maximum degree.

In LIS, many absolute adjectives include an iconic component that indicates that the maximum degree of the scale has been reached. Unlike their spoken language counterparts (and other, non-iconic adjectives in LIS), these signs do not allow for imprecise readings (Aristodemo and Geraci 2015). For instance, the LIS equivalent of the English sentence this glass of wine is full but you can still pour a bit more is not grammatical because the sign FULL iconically conveys the meaning that the glass is maximally full. The same effect can be obtained in spoken Italian by accompanying the adjective with a co-speech gesture (an open hand waving on the horizontal plane). This fact shows that an iconic component that is an obligatory part of a sign and an independent co-speech gesture in spoken language contribute similar core meanings to utterances.

In the examples discussed above (i.e. telicity and absolute gradable adjectives), there is an iconic/imagistic representation that is comprehensible to non-signers (as in the telicity example) and can optionally be employed during co-speech gesture (as in the absolute scale example). On the Goldin-Meadow and Brentari framework, one might therefore conclude that they are a part of the gestural system.

Nevertheless these representations are not variable across members within signing communities, and seem to play a key role in determining grammaticality. On these grounds, one might conclude that they are part of the "categorical" signing system.

This leaves open two possible theoretical positions, either of which would 
Running head: The categorical role of iconic signs

represent a substantial alteration of the Goldin-Meadow and Brentari framework. The first possibility is that we treat the markers of telicity and absolute scale in LIS as gesture. On this view gesture would be capable of interacting with the grammatical system of sign languages in highly intricate ways. In this case, we must accept that some types of gesture do not have a tendency to be variable across speakers within a language, that gesture is not necessarily holistic, and that gesture can have virtually identical functions to well known grammatical markers in spoken languages (such as event-finality in Slavic languages).

The second possibility is that we treat the markers of telicity and iconic absolute adjectives in LIS as being categorical elements of the signing system. On this view, one would need to accept that some properties of sign are highly iconic, and that overlap with co-speech gestures from spoken language should not be taken as a criterion for distinguishing sign from gesture.

For the moment, both views are plausible. Subsequent research and refinement of analytic techniques would be necessary to distinguish between them.

\section{Acknowledgements}

The research was supported by the European Research Council under the European Union's Seventh Framework Programme (FP / 2007-2013) / ERC Grant Agreement n.313610, ANR-10-IDEX-0001-02 PSL*, ANR-10-LABX-0087 IEC, and a Fyssen Foundation Postdoctoral grant. 
Running head: The categorical role of iconic signs

\section{References}

Aristodemo, V., Geraci, C. (2015) Comparative constructions and visible degrees in LIS. Talk given at FEAST 2015, Barcelona.

Goldin-Meadow, S., \& Brentari, D. (to appear). Gesture, sign and language: The coming of age of sign language and gesture studies. Behavioral and Brain Sciences.

Strickland, B., Geraci, C., Chemla, E., Schlenker, P., Kelepir, M., \& Pfau, R. (2015). Event representations constrain the structure of language: Sign language as a window into universally accessible linguistic biases. PNAS, 112 (19), 5968-5973.

Wilbur, R. B. (2003). Representation of telicity in ASL. Chicago Linguistic Society, 39(1), $354-368$.

Wilbur, R.B. (2008) Complex predicates involving events, time, and aspect: Is this why sign languages look so similar? In J. Quer (Ed.) Theoretical Issues in Sign Language Research, (pp 217-250). Signum Press, Hamburg. 